\title{
Drug related deaths in the community: A preventive role for accident and emergency departments?
}

\author{
John M Ryan, Isabelle Spronken
}

\begin{abstract}
Reducing drug related deaths has been identified as a priority by the British government. This study examined the link between drug related deaths in the community and prior contact with local accident and emergency (A\&E) services. Most drug related deaths were found among male opioid users in their early $30 \mathrm{~s}$ who had previously attended the local $A \& E$ department. It is suggested that $A \& E$ departments have a vital part to play, not only in the acute management but also in the prevention of drug related deaths in the community. Models for primary prevention, liaison and ongoing referral are discussed.

(F Accid Emerg Med 2000;17:272-273)
\end{abstract}

Keywords: dug related deaths; heroin

The number of opioid overdoses and drug related deaths among drug misusers continues to increase. ${ }^{1}$ Brighton and Hove coroner's jurisdiction has reported the highest drug related death rate per 100000 population of any coroner's jurisdiction in the United Kingdom. ${ }^{2}$

The British Government's strategy for tackling drug misuse has targeted the reduction of drug related deaths as one of its performance indicators. ${ }^{3}$ Health care personnel involved with drug addicts have a part to play in helping to control the effects of drug addiction. However, it has been suggested that the World Health Organisation recommendations in managing this problem are not currently being met and that we are not yet "on track" in reducing harm related to drugs. ${ }^{4}$

Drug misusers commonly attend accident and emergency (A\&E) departments with problems such as accidental overdoses, abscesses and withdrawal effects. ${ }^{5}$ However, no recent studies have specifically examined the association between $\mathrm{A} \& \mathrm{E}$ departments and drug related deaths in the community. There is a need therefore to gather data surrounding these deaths both locally and nationally to develop pro-active preventative strategies. This study explores the link between drug related deaths in the community and a local A\&E department and proposes a role for $A \& E$ departments as a gateway towards helping to prevent drug related deaths.

The aim of this study was (1) to investigate the characteristics of the association between drug related deaths as reported by the coroner and prior contact with $A \& E$ services and (2) to investigate the extent to which A\&E departments might have a part to play in preventing drug related deaths in the community.

\section{Methods}

The Brighton and Hove coroner's records were reviewed for the calendar year 1998. Details were collected on people for whom a verdict of death attributable to drug dependency or death attributable to non-dependent misuse of drugs had been passed. Suicide verdicts were excluded from the study. For each case identified, demographic details were collected as well as details about the types of drugs implicated in the death.

The A\&E department in Brighton has approximately 60000 new attendances per year and serves a catchment population of approximately 300000 people. The computerised records of the department were cross checked with information obtained from the coroner's records. Evidence of any previous contact with the A\&E department was sought. Records were available for attendances during the previous eight years. Where evidence of previous presentation was found $\mathrm{A} \& \mathrm{E}$ records were analysed further for the total number of attendances, presenting complaints, number of days between last attendance and death, and number of admissions to hospital.

The departmental social workers and psychiatric liaison team were also asked to examine their records for evidence of previous consultations.

\section{Results}

The coroner passed drug related death verdicts in 36 cases during 1998.

Thirty three were men and three were women with a mean age of 34 years and a range from 20 to 57 years. In $28(78 \%)$ cases there was a record of prior attendance at the A\&E department ranging from 2 to 36 attendances with a mean of six attendances. The types of presenting complaints were listed by A\&E medical staff as drug related in $44 \%$, orthopaedic/trauma in $27 \%$, medical in $15 \%$, psychiatric in $7 \%$, surgical in $2 \%$ and "others" $5 \%$. There was a total of 44 admissions to hospital among 16 people. Of this group there had been 23 admissions to the A\&E department short stay ward by 13 people.

Toxicology results indicating the types of drugs implicated in the deaths were available in 34 cases. In 16 cases, more than one drug was implicated. Heroin was involved on 20 occa- 
sions and was the single agent associated with death on 10 occasions. Other drugs included: morphine, cocaine and other opioids.

Six people were known to departmental social workers, and six to the psychiatric liaison team, of whom two were known to both professions.

Death occurred in 16 people (44\%) within one year of the last presentation to the $A \& E$ department with a mean of 112 days (ranging 3-340 days). For 12 people death occurred more than one year after their last presentation to the $\mathrm{A} \& \mathrm{E}$ department. (range $1-7$ years).

\section{Discussion}

Brighton and Hove coroner's district has the highest death rate attributable to dependency and non-dependent misuse of drugs of any coroner's jurisdiction in the UK. However, defining "drug related death" is difficult. Nationally, the problem may be greater than is recognised. For instance, important organisations such as the Office for National Statistics and the National Programme on Substance Abuse Deaths include different criteria in defining drug related deaths and these in turn may differ from individual coroners' verdicts. Nevertheless this need not detract from the fact that drug misusers continue to die prematurely from drug related activity.

This study has identified that drug related deaths in Brighton and Hove are a significant problem. It has also revealed certain characteristics that may help to identify persons at risk of premature death; most deaths were among men in their early 30 s and heroin was the most common drug implicated in deaths, though this may in itself reflect the sex and age characteristics of opioid users.

Clearly the local A\&E department is a common denominator for many of these people; almost $80 \%$ having had a presentation to the department at some stage in the past, with $60 \%$ in the past year. Indeed the A\&E department was significantly involved in the management of 13 of the 36 people identified in this study when they had been admitted to the A\&E department short stay ward. It would seem from our findings that increased resources should be allocated to A\&E departments to tackle the problem of drug related harm and to improve the potential of preventing drug related deaths.

\section{WHAT RESOURCES?}

The profile of a victim of a drug related death is easy to describe. The person is likely to be male in his early 30s with a history of opioid misuse.

Approximately one third of the people had stayed at some time in the short stay ward, but only half were known to either social workers or the psychiatric liaison nurses. It is apparent that there is a significant role in $A \& E$ departments for information provision, health education and referral of drug misusers for appropriate aftercare to the local drug depend- ency unit. It would also seem that currently these opportunities are being under-utilised by A\&E departments. For instance, Williams et al found that among Ecstasy users presenting to an $A \& E$ department very few were given preventive advice or referral. ${ }^{6}$ We propose that $\mathrm{A} \& \mathrm{E}$ departments should provide "trigger mechanisms" that would serve to alert social services, the psychiatric liaison team and substance misuse services when an "at risk" patient presents to the department. In particular patients admitted to an A\&E short stay ward should be screened for drug misuse and appropriate interventions offered to them when misuse is identified. Advice should be offered in keeping with that suggested by the Department of Health's document on the clinical management of drug misuse and dependence. ${ }^{7}$ Of course this has significant resource and cost implications but such a role could perhaps be incorporated by a multidisciplinary self harm team. ${ }^{8}$ Alternatively it could be adopted by a drug and alcohol worker similar to services provided by alcohol workers elsewhere. $^{9}$

\section{Conclusions}

Patients who present to A\&E departments with drug related morbidity seem to be at significant risk for subsequent drug related deaths and they should be provided with appropriate direction and advice. A\&E departments may have a part to play in preventing drug related deaths in the community by virtue of their relatively frequent interaction with this population. Further research in this area is warranted to assess the impact of interventions in $\mathrm{A} \& \mathrm{E}$ on drug related deaths in the community.

The authors acknowledge the help given by Ms Veronica Hamilton-Deeley the Brighton and Hove Coroner and her clerks, and the Social Workers and Psychiatric Liaison nurses at the Royal Sussex County Hospital in the preparation of this paper.

Funding: none.

Conflicts of interest: none.

Contributors

J Ryan devised the study, designed the methodology, participated in data collection and in writing and editing the paper. He is the guarantor for the paper. I Spronken performed the literature review, participated in the data collection and analysis and in the writing of the paper.

1 Schwartz RH. Adolescent heroin use: a review. Pediatrics 1998;102:1461-6.

2 Ghodse H, Clancy C, Oyefeso A, et al. Drug related deaths as reported by coroners in England E Wales, Fuly-December 1997. London: St George's Medical School, 1998.

3 Tackling drugs. To build a better Britain. London: UK ADCV, 1998.

4 Fischer B, Kendall P, Rehm J, et al. Charting WHO - goals or licit and illicit drugs for the year 2000: are we 'on track'? Public Health 1997:111;271-5.

5 Cook S, Moeschler O, Michaud K, et al. Acute opiate overdose: characteristics of 190 consecutive cases. Addiction 1998;93:1559-65.

6 Williams H, Dratcu L, Taylor R, et al. "Saturday night fever": Ecstasy related problems in a London accident and

7 Department of Health. Drug misuse and dependence-guidelines Department of Health. Drug misuse and dependence-guidelines
on clinical management. Norwich: Her Majesty's Stationery Office, 1999.

8 Ryan J, Clemmett S, Perez-Avila C. Managing patients with deliberate self harm admitted to an accident \& emergency observation ward. F Accid Emerg Med 1996;13:31-3.

9 Wright S, Moran L, Meyrick M, et al. Intervention by an alcohol health worker in an accident and emergency department. Alcohol 1998;33:651-6. 